\title{
Erratum zu Kapitel 4.3 Linearität (A3, A4)
}

\section{Erratum zu:}

Kapitel 4.3 in: D. Urban und J. Mayerl, Angewandte Regressionsanalyse: Theorie, Technik und Praxis, Studienskripten zur Soziologie, https://doi.org/10.1007/978-3-658-01915-0_4

\section{Auf Seite 199 ist uns ein Satzfehler unterlaufen. Wir bitten, dies zu entschuldigen. Der Absatz lautet korrekt:}

In Abbildung 4.6 sind die Residuen bis zum Wert $\mathrm{X}_{\mathrm{i}}$ negativ (d. h. sie liegen unterhalb der Regressionsgeraden). Sie werden dann im Bereich zwischen $X_{i}$ und $X_{k}$ positiv (d.h. sie liegen oberhalb der Regressionsgeraden) und werden im Bereich rechts von $X_{k}$ wiederum negativ (d.h. sie liegen dort wieder unterhalb der Regressionsgeraden). Die Residuen folgen also einer bestimmten Regelmäßigkeit, die darauf hinweist, dass in diesem Modell der „,wahre“ Zusammenhang zwischen den Messwerten von Y und X nicht linear ist.

Die aktualisierte Originalversion des Kapitels kann hier abgerufen werden https://doi.org/10.1007/978-3-658-01915-0_4

(C) Springer Fachmedien Wiesbaden GmbH, ein Teil von Springer Nature 2018

D. Urban und J. Mayerl, Angewandte Regressionsanalyse: Theorie,

Technik und Praxis, Studienskripten zur Soziologie,

https://doi.org/10.1007/978-3-658-01915-0_10 